\title{
Comentarios
}

\section{Fragilidad institucional y proceso de democratización}

El propósito de estas líneas es reflexionar, teniendo en la mira el caso de El Salvador, sobre la importancia y necesidad de un sólido entramado institucional para el sostenimiento de un régimen político democrático. Y es que cada vez gana más aceptación la tesis de que la democracia, para mantenerse a lo largo del tiempo, requiere de un entramado institucional que la sostenga y contribuya a la reproducción de sus normas y valores. Como dice Robert Dahl: "si un país ha de gobernarse democráticamente, ¿qué sería necesario? Como mínimo, debería poseer ciertos arreglos, prácticas e instituciones políticas, que significaran un importante avance, aunque no completo, hacia la consecución de criterios democráticos ideales"'. Eso no sólo lo demuestran las democracias más antiguas -Inglaterra, Francia, Estados Unidos, los Países Bajos- y las democracias en proceso de consolidación -Chile, Argentina, Uruguay-, sino también las democracias incipientes -El Salvador, Guatemala, Honduras, Perú-, amenazadas permanentemente por la reversión autoritaria. Si en las primeras es la fortaleza institucional la que explica la permanencia de la democracia, en las segundas es justamente la debilidad institucional la que explica el atascamiento del proceso de democratización, la pervivencia de patrones de comportamiento discrecionales en las altas esferas estatales, y la irrupción de prácticas y actitudes de claro signo autoritario.

En el caso concreto de El Salvador, el año 1999 ha sido aleccionador en cuanto a las dificultades por las que puede atravesar un proceso de democratización, toda vez que no se hayan afianzado con la suficiente solidez las instituciones que habrán de sostenerlo desde sus etapas iniciales hasta sus fases de mayor desarrollo. En nuestro país, la transición - esa etapa de establecimiento de los mecanismos básicos para la edificación de un ordenamiento democrático - no ha preparado el terreno para la consolidación de un sistema democrático - la fase de reconocimiento y puesta en práctica de los derechos civiles y políticos de los ciudadanos - Entre ambos momentos, se ha operado una especie de ruptura que alimenta el pesimismo y la incertidumbre acerca del futuro de la democratización en El Salvador. La traducción social de esa ruptura se pone de manifiesto en la creciente desconfianza de los salvadoreños hacia la política y los políticos, de los cuales ni se espera que entiendan los problemas que aquejan a la mayor parte de la población ni mucho menos que sean capaces de encauzar debidamente las demandas en que los mismos se expresan.

Una de las razones de esa desconexión entre transición y consolidación es la debilidad del tejido institucional, lo cual ha llevado a que instituciones que son claves para la democratización del país - la Asamblea Legislativa, la Procuraduría para la Defensa de los Derechos Humanos (PDDH) y la Policía Nacional Civil (PNC), entre otras- o bien hayan terminado siendo inoperantes, o bien hayan visto pervertidos sus objetivos fundamentales. Ni qué decir de instituciones surgidas antes de los acuerdos de paz, como la Corte de Cuentas de la República o el Órgano Judicial: éstas ni han logra-

1. Ver Robert Dahl, La democracia. Una guía para los ciudadanos, Madrid, Taurus, 1999, p. 97. 
do superar vicjos vicios, entre los que destacan la ineficiencia y la corrupción, ni han logrado asumir de lleno las responsabilidades que les competen en la lase actual del proceso sociopolítico salvadoreño. Lo peor de todo es que otras instituciones -como por ejemplo, el Ministerio del Interior- abiertamente le han hecho la contra al proceso de democratización, tomando decisiones e implementando medidas de claro corte autoritario.

Del primer grupo de instituciones, quizás la que menos ha contribuido a la democratización del país ha sido la Asamblea Legislativa. Esta instancia, en cuyo seno se toman decisiones fundamenlales para la vida de más de 5 millones de seres humanos (supuestamente "representados" por los micmbros de cse órgano del Estado), está integrada por individuos que, salvo contadas excepciones, no tienen en mente más que los beneficios que ellos y los partidos a los que sirven pueden obtener durante su ejercicio legislativo. Se trata, en su mayoría, de individuos —además de ambiciosos y faltos de todo compromiso con la marcha global del país- con notorias limitaciones intelectuales y con escasas habilidades técnicas. Pero, por absurdo que ello sea, a estas personas -que no sólo son las que menos saben acerca de lo que le conviene a El Salvador, sino que son a las que eso menos les preocupa- reciben de los salvadoreños un jugoso salario, amén de prestaciones adicionales, para que decidan por ellos (por lo general mal) acerca de problemas que afectan vitalmente a todos. Para muestra un botón: los sesudos diputados aprobaron, dando muestras de una irresponsabilidad sin límites, una ley de armas que elevará los niveles de violencia en el país, con lo cual decidieron en contra de la seguridad y la vida de sus habitantes.

Una segunda institución que, al ver pervertidos sus objetivos, no ha contribuido a la democratización de El Salvador es la Procuraduría para la Defensa de los Derechos Humanos (PDDH). Esta institución, creada en el marco de los acuerdos de paz para garantizar los derechos de los ciudadanos frente al Estado, ha caído en la irrelevancia y el desprestigio más absolutos. Los cimientos institucionales que comenzaron a enraizarse bajo la administración de Victoria de Avilés se han venido abajo con el nuevo procurador Eduardo Peñate Polanco, cuya incompetencia ha sido probada hasta la saciedad. El mismo procurador se ha cncargado de poner en evidencia su mediocridad en diversas ocasiones, como cuando tuvo que auxiliarse de un asistente para que le dictara las respuestas para los reporteros que lo interrogaban. Sin embargo, Peñate Polanco sigue, aun después de los presuntos arreglos políticos que llevarían a sus destitución, inamovible en su cargo, sin importar las abundantes razones que se han esgrimido para revocarle su mandato. Aquí también, absurdamente, los salvadoreños pagan un salario a un funcionario (y también a su séquito de incondicionales) que no sirve para nada y que, además, hace un serio daño a la institucionalidad del país.

En tercer lugar, la Policía Nacional Civil (PNC), instilución que ha venido cargando con una serie de vicios adquiridos desde los momentos iniciales de su constitución y que, en estos momentos, son un lastre del que no puede desprenderse si no es a partir de una drástica puesta al día con los principios -inspirados en los acuerdos de paz- que deberían regir su trabajo cotidiano. Pocos ponen en duda las manipulaciones a las que fue sometida la PNC en sus momentos iniciales por parte de la administración de Alfredo Cristiani. En buena medida, esta administración se salió con la suya al integrar a ex miembros de los desaparecidos cuerpos de seguridad -especialmente de la Policía Nacional - a la nueva institución policial. Pero no sólo eso: junto con los agentes integrados, iban lealtades y estilos de comportamiento contrarios a la vocación democrática que se le pretendía imprimir a la Policía Nacional Civil. Así, gérmenes autoritarios se incrustaron en la nueva policía sin que hasta el día de hoy hayan dejado de hacer sentir sus efectos nocivos ${ }^{2}$. Las dos caras visibles de la presencia de esos gérmenes autoritarios son, por un lado, el involucramiento de agentes policiales en hechos criminales de diversa naturaleza -desde narcotráfico hasta secuestros- $y$, por otro, la tendencia a hacer prevalecer, por sobre la dimensión preventiva, la dimensión coercitiva de la seguridad pública.

En más de una oportunidad, el ejercicio de la coerción policial no ha sido empleado sólo para combatir a la criminalidad, sino también para controlar protestas sindicales y laborales, con lo cual las funciones de garante de la seguridad ciudadana del cuerpo policial han sido puestas en entredicho.

2. Ver Gino Costa, La Policia Nacional Civil de El Salvador (1970-1997). San Salvador, UCA Editores, 1999. 
Con el arribo de Mauricio Sandoval a la jefatura de la Policía Nacional Civil, la dimensión coercitiva ha cobrado un perlil más evidente en el trabajo policial. alcjando aún más a la instilución del ideal de policía resguardo de la democracia que se delineó en los acuerdos de par .

En otro orden, instituciones como la Corle de Cuentas de la República - jun10 con la Procuraduría para la Defensa de los Derechos Humanos- son las que mejor rellejan lo mal que anda El Salvador a nivel de su funcionamiento institucional. En clecto, la Corte de Cuentas, lejos de cumplir con sus tareas de liscalización de las finanzas públicas, sirve para lo contrario: ocultar y amparar la corrupción que se ge-

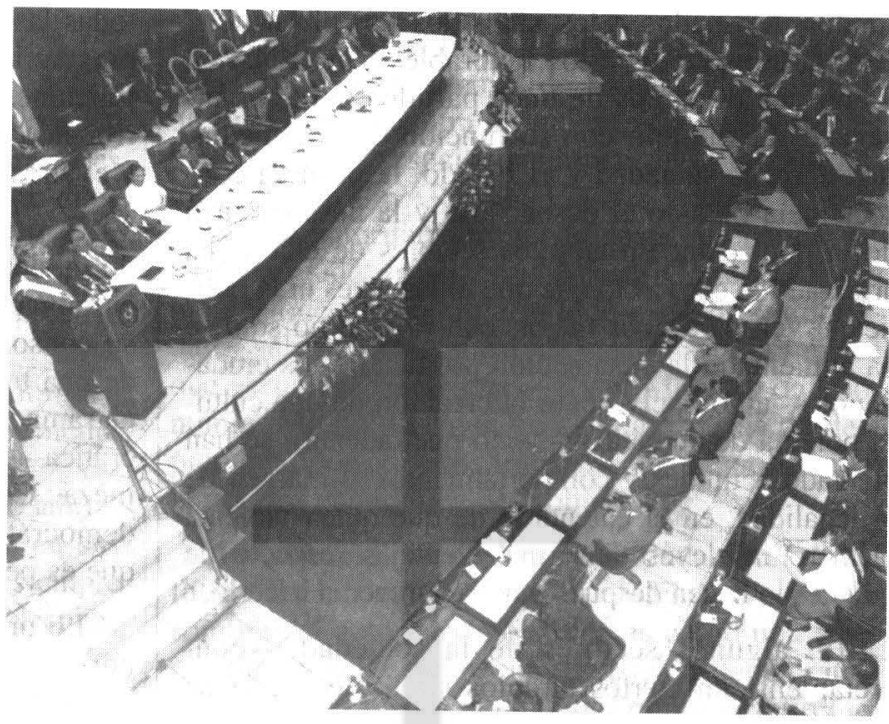
nera en los diversos ámbitos del gobierno, sobre todo en sus niveles superiores. En virtud de un "pacto" que en nada favorece los intereses del conjunto de los salvadoreños, tres partidos - ARENA, Partido Demócrata Cristiano y Parlido de Conciliación Nacional- decidieron repartirse entre sí tres instituciones decisivas para la marcha del país, una de las cuales es la Corte de Cuentas (las otras dos son la Fiscalía General y la Procuraduría Gencral), misma que ha sido asignada al PCN. El "pacto", por supuesto, está pensado para favorecer los intereses de quienes lo han suscrito, y no los intereses del conjunto de la población. De aquí que, mientras ese "negocio" siga en pie, no sólo van a continuar reinando en la Corte de Cuentas funcionarios incompetentes y corruptos, sino que cl público nunca va a ser informado del modo en que son usados los recursos financieros del Estado - los recursos de todos los salvadoreños- en las diferentes áreas gubernamentales. De seguir así las cosas, nunca se sabrá cómo han gastado (o malgastado) los recursos públicos de las administraciones de Alfredo Cristiani y Armando Calderón Sol. Y ello porque el organismo contralor con el que se cuenta en el país hará todo lo que esté a su alcance para ocultar la información al respecto.

Por su vocación autoritaria, mención especial merece el Ministerio del Interior. De esta instancia de gobierno han emanado iniciativas claramente autoritarias. $\mathrm{Y}$ es que el Ministerio del Interior, de la mano de Mario Acosta Oertel, no sólo pretende concentrar una cantidad de información acerca de

los salvadoreños - a través de los registros de pasaportes-, sino, además, controlar los gustos y preferencias musicales de los habitantes de El Salvador. Hay que recordar que esta cartera de Estado, con la prepotencia que la caracteriza, "sugirió" (es decir, ordenó) a los medios radiales que retiraran del aire música contraria a la "moral", el "orden" y las "buenas costumbres" de los salvadoreños. Y la Asociación Salvadoreña de Radiodifusores (ASDER), que en más de una ocasión ha pregonado la libertad de expresión, se sometió sin resistencia alguna - sino más bien todo lo contrario- a la "petición" oficial.

En los años setenta y ochenta, los gobiernos de turno censuraban la música - también los libros y las películas- que consideraban subversiva y ello con la venia de gremiales como ASDER. En los años noventa, cuando se cree que por fin se va a dejar atrás el autoritarismo, la pretensión estatal de controlar la conciencia de los ciudadanos ha vuelto a aparecer, y nuevamente cuenta con el visto bueno de la ASDER. He aquí lo absurdo de la situación: quienes dicen defender la libertad de expresión (y su contraparte: la libertad de recepción) aplauden decisiones que van en contra de esa libertad.

La contrapartida de las tendencias autoritarias emanadas del aparato estatal han sido el malestar y el recelo sociales. Ante unas medidas económicas diseñadas e implementadas a espaldas de los sectores mayoritarios del paŕs — los más golpeados por sus efectos-; ante prácticas ilícitas gestadas en el seno del gobierno - por ejemplo, el desvío de 
fondos destinados a los afectados por el "Mitch" para la compra de votos favorables a ARENA-; $y$ ante los desatinos de unos partidos políticos incapaces de cumplir con su función de intermediarios entre la sociedad y el Estado, la primera consecuencia ha sido el desencanto y la desconfianza de la población. En amplios sectores de ella se ha arraigado la convicción de que ni las leyes ni la política sirven para vivir mejor, con lo cual no sólo se ha alimentado la desafección política de los ciudadanos - algo nocivo para la creación de una cultura política democrática-, sino que, además, se han alentado actitudes y comportamientos al margen de la legalidad, en el entendido de que quien violenta primero las leyes tiene más ventajas respecto de quienes lo hacen después o no se atreven a hacerlo.

En algunos sectores de la sociedad -concretamente en ciertos círculos sindicales-, se ha terminado por aceptar que el único modo de hacer prevalecer los derechos de los trabajadores es a través de las medidas de fuerza. Esto ha dado lugar a comportamientos y actitudes militantes, poco dispuestas a negociar aquello que consideran aspectos fundamentales dentro de sus plataformas reivindicativas. El gobierno, tras haber creado las condiciones que llevaron a estos sectores laborales a asumir posiciones radicales - piénsese específicamente en los trabajadores del Seguro Social-, no ha tenido la capacidad para revertir la situación, diseñando una solución que sea favorable a todos los involucrados. Con tozudez, las autoridades gubernamentales se han plantado con igual determinación que los trabajadores en llevar hasta las últimas consecuencias sus respectivas posturas. Hasta ahora, la fuerza y la prepotencia han terminado por ganarle la partida a la razón y a la flexibilidad.

Así, pues, una evaluación del año 1999 no puede dejar de señalar, como un rasgo característico de la realidad nacional, la grave debilidad institucional que corroe a instancias que son fundamentales para la construcción de una sociedad democrática. Basta dar un vistazo a instancias como la Asamblea Legislativa, la Procuraduría para la Defensa de los Derechos Humanos, la Policía Nacional Civil, el Ministerio del Interior y la Corte de Cuentas para alimentar el pesimismo más radical. $\mathrm{Y}$ es que El Salvador no tiene viabilidad alguna como nación abierta a los desafíos del futuro con una institucionalidad tan endeble y maltratada, como la que en la actualidad lo caracteriza. No tenemos alternativa: o saneamos de una vez por todas las instituciones del Estado y nos preocupamos seriamente porque cumplan a cabalidad sus funciones, o continuamos empantanados en la corrupción, los intereses mezquinos, la mediocridad y el atraso sociocultural, económico y político.

Es esa debilidad institucional la que ha impedido, a siete años de firmados los acuerdos de paz, culminar la transición democrática y avanzar hacia su consolidación. En otras palabras, se ha tratado de una transición incompleta, cuyos cimientos -el entramado institucional básico para la vida democrática - no han sido afianzados con la debida firmeza. Como resultado de ello, la consolidación democrática no puede ni darse por terminada ni, lo que es peor, darse por segura.

Lo primero -el no haber alcanzado todavía la consolidación democrática-, aunque preocupante, no es lo peor que puede pasarle al país, puesto que lo que sigue de ello es el imperativo de trabajar por superar aquellos obstáculos que hasta el momento lo han impedido. Otras sociedades se encuentran ante retos parecidos y eso no desdice en lo absoluto de su vocación democrática. Lo segundo -que el avance hacia la consolidación no esté asegurado-, en cambio, es grave en un doble sen(ido: ante todo, porque la debilidad institucional es de tal magnitud, que no garantiza que vaya a implantarse un Estado de derecho que en verdad sea tal; es decir, que haga prevalecer la ley por encima de los intereses de grupos e individuos particulares y que garantice a todos los ciudadanos una vida digna, sin exclusiones de ningún tipo. Así, pues, el Estado de derecho es una condición fundamental para dar por lograda la consolidación democrática y mientras sus cimientos institucionales no hayan sido establecidos, aquélla será una tarea pendiente.

Pero, en segundo lugar, porque la debilidad institucional abre las puertas a actitudes y comportamientos autoritarios del más diverso signo, los cuales emanan de grupos e individuos enquistados en las estructuras estatales que se sienten muy por encima de la legalidad. En otras palabras, la debilidad del entramado institucional abre las puertas a la discrecionalidad en las altas esferas del aparato estatal, con todos los riesgos que esto trae consigo: por un lado, prepotencia e impunidad; $y$, por otro, malestar y recelo sociales.

En un contexto como el descrito, ha cobrado fuerza la posibilidad de que emerja un líder carismático que ofrezca, al margen de los mecanis- 
mos democráticos, una solución definitiva a los problemas de El Salvador. Muchas figuras políticas, militares y empresariales, no ocultan sus simpatías por una salida de ese tipo; e incluso no es descabellado suponer que más de alguno de ellos esté pensado en erigirse como el redentor del país. Que esa posibilidad se haya hecho presente dice hastante de lo desencaminado que anda el proceso de democratización en El Salvador. Que haya quienes estén dispuestos a hacer de esa posibilidad una realidad dicc mucho del escaso afianzamiento de los valores democráticos en nuestro país. A estos últimos habría que recordarles que las salidas autoritarias, por muy loables que parezcan en sus propósitos y en su voluntad de cambio, siempre terminan siendo malas soluciones, aunque despierten los mayores entusiasmos populares: al líder autoritario, llámesc Hugo Chávez, Fidel Castro o Alberto Fujimori, nadie lo controla y, en consecuencia, puede hacer y deshacer a su antojo lo que a bien le parezca, poniéndose por encima de los Jemás -incluyendo a quienes hasta el día de ayer cran sus aliados-y violentando sus derechos.

Por otra parte, el riesgo autoritario es sólo eso: un riesgo que, en buena medida, se explica por la debilidad institucional de la que adolece el país en el momento actual. Otra de la razones que lo explican es el escaso arraigo de los valores democráticos en amplios sectores de la sociedad, lo cual, además, se ve agravado por la difusión de valores y actitudes autoritarias desde las esferas gubernamentales. De aquí que para hacer frente a la amenaza autoritaria, en primer lugar, se tenga que trabajar por fortalecer el entramado institucional del país; en segundo lugar, se deba trabajar por la creación y difusión de una cultura política democrática, que dé pie a opciones y valores contrarios al autoritarismo; $y$, en tercer lugar, se deba sanear al Estado y al aparato de gobierno de todos aquellos funcionarios cuyo compromiso con las soluciones autoritarias es inocultable.

El año 1999 ha sido aleccionador en varios sentidos: funcionarios de alto rango, incluido el presidente Francisco Flores, han hecho alarde de actitudes y comportamientos no sólo discrecionales - amparados más en los dictados de su volun- tad que en lo que dicen las leyes-, sino de claro signo autoritario: además de amenazar, han tomado medidas en contra de quienes no comparten el credo polílico y socioeconómico de la tercera administración de ARENA. Figuras señeras en este escenario autoritario fraguado desde el aparato estatal han sido el Ministro Acosta Oertel, con sus pretensiones de controlarlo todo -desde las entradas y salidas al territorio nacional, hasta la música que escuchan los jóvenes-, y el Ministro de Economía, Miguel Lacayo, con sus amenazas de despido de todos aquellos trabajadores que no acepten la política económica del gobierno.

En suma, 1999 deja muchas dudas acerca del futuro de la democratización en El Salvador. La sombra del autoritarismo se cierne como una amenaza inobjetable sobre una transición democrática incompleta. El año 2000 plantea como desafío ineludible completar la transición y avanzar decididamente hacia la consolidación democrática. Sin embargo, eso no podrá hacerse sin un compromiso del conjunto de la sociedad -0 al menos de amplios sectores de la misma- con los valores y opciones democráticos. Este compromiso es el mejor antídoto contra las opciones autoritarias, sean del signo que sean. No es fácil comprometer democráticamente a una sociedad golpeada por el impacto de las medidas de privatización e insatisfecha con el desempeño de la clase política. Quizás una recomposición del tejido institucional del país pueda contribuir a fomentar la confianza perdida en las leyes, sus gestores, sus guardianes y sus ejecutores. Obviamente, una recomposición institucional supone no sólo un cambio en las estructuras institucionales propiamente dichas -en sus funciones y objetivos fundamentales-, sino también en las opciones y valores de quienes las dirigen. Mientras este cambio de mentalidad y conducta no se opere en la línea de los valores y la opciones democráticos —es decir, mientras los responsables de dirigir las instituciones del país continúen siendo discrecionales y prepotentes-, El Salvador seguirá entrampado en una transición incompleta y sometido a la amenaza de la reversión autoritaria.

Luis Armando González 